\title{
A Review of Nutritional Factors in Hypertension Management
}

\author{
Ha Nguyen, ${ }^{1}$ Olaide A. Odelola, ${ }^{1}$ Janani Rangaswami, ${ }^{1}$ \\ and Aman Amanullah ${ }^{2}$ \\ ${ }^{1}$ Department of Medicine, Albert Einstein Medical Center, Philadelphia, PA 19141, USA \\ ${ }^{2}$ Noninvasive Cardiology, Albert Einstein Medical Center, Clinical Professor of Medicine, \\ Jefferson Medical College of Thomas Jefferson University, 5501 Old York Road, \\ HB-3, Philadelphia, PA 19141, USA \\ Correspondence should be addressed to Aman Amanullah; amanullaha@einstein.edu
}

Received 1 January 2013; Accepted 15 March 2013

Academic Editor: Mario Fritsch Neves

Copyright (c) 2013 Ha Nguyen et al. This is an open access article distributed under the Creative Commons Attribution License, which permits unrestricted use, distribution, and reproduction in any medium, provided the original work is properly cited.

Hypertension is a major health problem worldwide. Its attendant morbidity and mortality complications have a great impact on patient's quality of life and survival. Optimizing blood pressure control has been shown to improve overall health outcomes. In addition to pharmacological therapies, nonpharmacological approach such as dietary modification plays an important role in controlling blood pressure. Many dietary components such as sodium, potassium, calcium, and magnesium have been studied substantially in the past decades. While some of these nutrients have clear evidence for their recommendation, some remain controversial and are still of ongoing study. Dietary modification is often discussed with patients and can provide a great benefit in blood pressure regulation. As such, reviewing the current evidence will be very useful in guiding patients and their physician and/or dietician in decision making. In this review article of nutritional factors in hypertension management, we aim to examine the role of nutritional factors individually and as components of whole dietary patterns.

\section{Introduction}

In adults aged 18 years and older, hypertension is defined as a systolic blood pressure (SBP) equal or more than $140 \mathrm{mmHg}$ and/or diastolic blood pressure (DBP) equal or more than $90 \mathrm{mmHg}$ based on the mean of 2 or more properly measured seated blood pressure readings on each of 2 or more office visits by the seventh report of the Joint National Committee on Prevention, Detection, Evaluation, and Treatment of High Blood Pressure (JNC) [1]. According to the 2012 World Health Statistics report released by the World Health Organization (WHO), hypertension affects approximately $24.8 \%$ of the global population with the range from $19.7 \%$ to $35.5 \%$ in different regions [2]. It is one of the most common diseases that lead to office visits or hospitalizations and a major risk factor for stroke, congestive heart failure (CHF), myocardial infarction (MI), peripheral vascular disease, and overall mortality. Many of those with hypertension are undiagnosed, and of those detected, about two-thirds are suboptimally controlled [1]. Early treatment can improve blood pressure and its complications significantly [1]. Therapeutic options include diet and lifestyle changes (including weight loss, smoking cessation, and increased physical activity), antihypertensive drugs, and surgery in special situations.

Clinical and population-based studies show that several components of the diet such as sodium, potassium, calcium, magnesium, fiber, and fish oil affect blood pressure, and modification of these nutritional factors provide an important strategy to control blood pressure especially in the prehypertensive stage (SBP $120-139 \mathrm{mmHg}$ and/or DBP $80-89 \mathrm{mmHg}$ ) or stage I hypertension (SBP $140-159 \mathrm{mmHg}$ and/or DBP 90-99 $\mathrm{mmHg}$ ). The role of these dietary factors singly or in combination in blood pressure regulation and to what extent each contributes has been a subject of research for many decades, and despite this, it remains controversial. Modifying one's diet can be a difficult and significant change 
in life, and many patients oppose this or fail despite several attempts. Given how frequently clinicians have to provide patients with this recommendation and the potential impact on the overall outcome in patient health, it is of great benefit to study the current evidence in nutritional approach to hypertension management. In this paper, we aim to review the role of each individual dietary factor as well as whole dietary patterns.

\section{Sodium}

The relationship between sodium intake and blood pressure changes has been a topic of discussion for decades. Hypertension is predominantly observed in societies with average sodium chloride intake $>100 \mathrm{mmol} /$ day and very rare in populations consuming $<50 \mathrm{mmol} /$ day $[3,4]$. However, the link between salt and hypertension is still an ongoing debate. The concept of salt sensitivity versus salt resistance originated from studies demonstrating heterogeneous blood pressure responses to changes in sodium intake. These changes were observed both in hypertensive and normotensive subjects [58]. Till date, there is no uniformed definition of salt sensitivity due to great variations in published studies regarding study protocols, techniques, duration, and magnitude of sodium intake and blood pressure changes. However, the most commonly used method was introduced by Weinberger [9]. Based on mean arterial blood pressure response to sodium load by intravenous administration of 2 liters of normal saline and sodium depletion by a $10 \mathrm{mmol}$ sodium diet and 3 doses of oral furosemide ( $40 \mathrm{mg}$ each), the authors arbitrarily classified salt sensitivity as a decrease in mean arterial pressure $\geq 10 \mathrm{mmHg}$ and salt resistance as a decrease $\leq 5 \mathrm{mmHg}$ when comparing the 2 blood pressure measurements.

As a brief review of physiology, sodium homeostasis is maintained by glomerular filtration and tubular reabsorption. Sixty-five to seventy-five percent of sodium reabsorption is mediated by neurohumoral hormone in the proximal (angiotensin II and norepinephrine) and collecting tubules (aldosterone, atrial natriuretic peptide), whereas 30-35\% occurs in the loop of Henle and distal tubules and this is flow dependent. A parallel adaptation in renal tubular activity in response to alterations in glomerular filtration of sodium keeps little variation in urinary sodium excretion [10]. This explains a steady range of sodium level even in cases of advanced kidney failure.

Salt sensitivity has been found to have a higher prevalence in certain populations: older age [11, 12], blacks [12], insulin resistance [13, 14], microalbuminuria [15], chronic kidney disease (CKD) [16], and low renin level [17, 18]. Recent animal and molecular studies have suggested the contribution of certain genetic polymorphisms to the development of salt sensitive hypertension via different mechanisms: affecting renal tubular $\mathrm{Na}+\mathrm{K}+\mathrm{ATPase}$ activity $[19,20]$, decreasing dopamine receptor function in renal proximal tubule [21], or altering endothelin receptor activity [22]. Salt sensitivity has been reported to be an independent prognostic factor for increased risk of left ventricular hypertrophy [23], cardiovascular events [24], and cumulative mortality [25], regardless of blood pressure.
Dietary sodium restriction is strongly advocated as a lifestyle behavioral change for prevention and treatment of hypertension and consequently cardiovascular morbidity and mortality by several professional organizations [1, 26-28]. Despite an abundance of studies on its efficacy, results are conflicting and naturally provoke questions on the benefits of continuing to advocate this intervention to patients $[29,30]$.

Evidence from several clinical studies shows that a reduction in sodium intake leads to modest to large reduction in blood pressure in normotensive and hypertensive participants [31-36] as well as decreased risk of cardiovascular events [37-39].

The INTERSALT study, a population-based study across 52 centers from 32 countries, examined the relationship between sodium excretion and blood pressure among over 10,000 participants. Sodium excretion was highly variable $(0.2-242 \mathrm{mmol} / 24$ hour $(\mathrm{hr}))$, with 4 centers having very low levels $(0.2-51.3 \mathrm{mmol} / 24 \mathrm{hr})$. A significant positive association between sodium excretion and blood pressure in individuals was reported overall. However, with exclusion of data from the 4 centers with the lowest excretion, no relation could be found [4].

The Dietary Approaches to Stop Hypertension (DASH)sodium trial randomized subjects to either the DASH diet (rich in fruits, vegetables, and low-fat dairy and reduced in saturated and total fat) or a control diet (typical United States (US) diet which is high in fat and low in fruits, vegetables, and dairy products) with participants consuming a graded sodium intake (high, intermediate, low) within each group during the study period. The study demonstrated significant dose-response decreases in SBP and DBP overall and blunting of the age-related increase in blood pressure with sodium restriction. The DASH diet and sodium restriction each lowered blood pressure substantially, but the effect was greater when combined $[35,36]$.

Investigators on a prospective followup study of participants in the trials of hypertension prevention phase I and II for $10-15$ years found a $30 \%$ and $20 \%$ risk reduction of cardiovascular disease (MI, stroke and coronary revascularization) and cardiovascular death, respectively, but the reduction in death was not statistically significant [37].

In contrast, several studies demonstrate harmful effects of lower salt intake on important clinical outcomes including MI [40], all-cause and cardiovascular mortality [41, 42], sympathetic hormones $[43,44]$, fasting plasma glucose and insulin levels $[44,45]$, cholesterol $[43,44,46]$, and in addition, higher CHF readmissions and brain natriuretic peptide levels $[47,48]$. Higher mortality $[49,50]$ and development of end stage renal disease (ESRD) [49] have also been reported with lower sodium intake among diabetics.

All together, despite several years and high magnitude of population-based studies and clinical research, the evidence supporting the recommendation of dietary sodium restriction should be interpreted with caution.

Given that salt restriction is not a "one size fits all" approach, differentiating individuals with salt sensitive and salt resistant hypertension would be beneficial. However, subjecting all hypertensive patients to salt sensitivity testing as in research protocols seems inconvenient and unfeasible. 
Thus, the question appears to be how physicians can clinically determine salt sensitivity. To address this query, a couple of studies have suggested ambulatory, however, indirect methods in evaluating salt responsiveness. De la Sierra and coinvestigators reported that patient's performance on ambulatory blood pressure monitoring could be a useful tool to assess salt sensitivity [51]. In their study, salt sensitive patients exhibited a nondipper profile on both low salt and high salt diets, while salt resistant subjects with high salt intake had increased blood pressure during sleep with no significant changes in the $24-\mathrm{hr}$ blood pressure. Galletti et al. found that in salt sensitive patients, there was a strong correlation between 24-hr urinary sodium excretion and blood pressure changes [52]. In another study, involving 89 Caribbean Hispanic hypertensive patients, plasma renin level was used to evaluate patient's response to antihypertensive therapy [53]. Sixty-two percent of the patients had low renin essential hypertension and responded preferentially to monotherapy with hydrochlorothiazide or calcium channel blockers. A phase 4 randomized study testing Fludrocortisone administration in identifying salt sensitivity is currently underway [54]. These methods need to be validated by larger studies before being considered for routine tests in evaluating and/or guiding treatment in hypertensive patients.

Currently, based on available evidence, the WHO strongly recommends the restriction of daily sodium intake to less than $2000 \mathrm{mg}$ (or $5000 \mathrm{mg}$ salt) [55], while the AHA advises lower than $1500 \mathrm{mg}$ sodium (or $3800 \mathrm{mg}$ salt) per day [28].

\section{Potassium}

The association of potassium and blood pressure has been described in many studies. Potassium intake was found to be inversely related to both DBP and SBP in a populationbased study including 685 men and women who were predominantly Caucasian in Southern California, United States of America (USA) [56]. Similar result was illustrated in the Rotterdam Study [57], a big population-based study in which 3239 participants older than 55 years old were included. Patients with an increase in potassium intake of $1000 \mathrm{mg} /$ day had a $0.9 \mathrm{mmHg}$ lower SBP and a $0.8 \mathrm{mmHg}$ lower DBP. In a study by Krishna and Kapoor, potassium depletion was shown to be associated with a decrease in sodium excretion, plasma renin activity, and plasma aldosterone concentrations and an increase of $7 \mathrm{mmHg}$ in SBP and $6 \mathrm{mmHg}$ in DBP [58].

Several interventional studies have shown the positive effects of potassium supplementation on blood pressure reduction. Cappuccio and MacGregor reviewed 19 clinical trials in which oral potassium supplements significantly lowered SBP (mean of $-5.9 \mathrm{mmHg}, 95 \%$ confidence internal (CI), -6.6 to $-5.2 \mathrm{mmHg}$ ) and DBP (mean of $-3.4 \mathrm{mmHg}$, $95 \% \mathrm{CI},-4.0$ to $2.8 \mathrm{mmHg}$ ) [59]. A meta-analysis consisting of 27 potassium trials in adults with a minimum of 2 weeks duration also demonstrated a change in blood pressure with increased potassium intake: a mean of $-2.42 \mathrm{mmHg}$ (95\% CI, -3.75 to $-1.08 \mathrm{mmHg}$ ) in SBP and $-1.57 \mathrm{mmHg}$ (95\% CI, -2.65 to $-0.50 \mathrm{mmHg}$ ) in DBP pressure [60]. Dickinson and colleagues used stricter inclusion criteria and only selected 5 randomized controlled trials for their metaanalysis published in the Cochrane Database in 2006. The authors did not find a statistical significant effect of potassium supplementation on blood pressure. However, the argument of small number of subjects, short duration of followup, and substantial heterogeneity of these trials was discussed as a possible explanation for the finding of this meta-analysis [61].

The benefit of potassium intake on blood pressure reduction appears to be greater in patients with hypertension [59, 60], longer duration of supplementation [59], and concurrent high intake of sodium [62].

The magnitude of blood pressure reduction seems small in number but might be translated into a benefit in mortality from complications of hypertension. In a study of 6 different populations, the relative increase in 25-year mortality risk due to coronary heart disease was 1.17 (95\% CI, 1.14 to 1.20 ) per $10 \mathrm{mmHg}$ increase in SBP and 1.13 (95\% CI, 1.10 to 1.15) per $5 \mathrm{mmHg}$ increase in DBP. After adjustment for within-subject variability in blood pressure, this relative risk was 1.28 [63]. A $5 \mathrm{mmHg}$ decrease in DBP was reported to be associated with less than one-third of strokes $[64,65]$.

It is worth mentioning that some protective effects of high potassium intake on cardiovascular health might be independent of blood pressure. An analysis of sodium and potassium intake and mortality among US adults based on data from the third National Health and Nutrition Examination Survey (NHANES) showed that higher sodium intake was associated with increased all-cause mortality, while higher potassium intake seemed to be associated with lower mortality. Of note, this finding was independent of sex, age, hypertension, physical activity, and body mass index (BMI) [66]. In a 12year prospective study, a $10 \mathrm{mmol}$ increase in daily potassium intake was associated with a $40 \%$ reduction in the risk of stroke-associated mortality. This protective effect of potassium did not differ by other dietary variables and known cardiovascular risk factors (age, sex, blood pressure, blood cholesterol level, obesity, fasting blood glucose level, and cigarette smoking) [67].

The antihypertensive effect of potassium supplementation might be from various mechanisms: (1) natriuresis by inhibiting sodium reabsorption in the proximal renal tubules [68] and suppressing renin secretion [69], (2) normalization of the plasma level of digitalis like substance [70], (3) increased urinary volume excretion [70], (4) smooth muscle relaxation [71, 72] by increasing nitric oxide production [73] and/or by stimulating the rectifier $\mathrm{K}(+)$ channels resulting in potential membrane hyperpolarization and subsequently vasodilation [74], (5) suppression of free radical formation [75], and (6) protection against vascular injury in salt sensitive hypertension [76]. Which one of these mechanisms plays a predominant role in the reduction of blood pressure and/or cardiovascular mortality is not quite clear at this time.

Based on available data, the Institute of Medicine has recommended a potassium intake of $4700 \mathrm{mg}(120 \mathrm{mmol})$ a day as adequate intake for all adults [77]. A similar amount of daily potassium consumption was also suggested by the American Heart Association (AHA) in 2006 to achieve the potential benefit of blood pressure reduction [28]. The 2003 WHO/International Society of Hypertension statement on 
management of hypertension supported an increased dietary potassium intake although a threshold was not specified [78]. However, the suggested daily intake of potassium might be lower in patients who are prone to developing hyperkalemia such as those with impaired renal excretion of potassium from CKD, CHF, adrenal insufficiency, and medications use (angiotensin converting enzyme (ACE) inhibitors, angiotensin receptor blockers (ARB), potassiumsparing diuretics, trimethoprim, cyclosporine, heparin, etc.) These patients need to be monitored frequently.

In reality, the average intake of dietary potassium in many countries is relatively lower than recommended. As in a report from the third NHANES 1988-1994 study, estimated mean potassium intakes of adults in the USA ranged from 2900 to $3300 \mathrm{mg}$ in men and 2200 to $2400 \mathrm{mg}$ in women [28]. The NHANES data from 2003 to 2008 , the time span during which the above recommendations were issued, revealed that less than $2 \%$ of adults and approximately $5 \%$ of men in the USA met the recommendations for potassium intake (i.e., at least $4700 \mathrm{mg} /$ day) [79]. In European countries, the average daily potassium intake in adults was reported to be below $4700 \mathrm{mg}$. The number varied from $3200 \mathrm{mg}$ to $4000 \mathrm{mg} / \mathrm{day}$ in Finland [80] or from $2655 \mathrm{mg}$ to $3371 \mathrm{mg} /$ day in the United Kingdom [81]. In China, the mean intake of potassium was $1950 \mathrm{mg} /$ day in the urban and $1830 \mathrm{mg} /$ day in the rural diet [82].

Foods rich in potassium are vegetables, fruit, dairy products, nuts, and so forth. Natural source of potassium is preferable. Currently, pharmacological potassium supplementation is not recommended as a method to obtain the advised daily intake of potassium.

\section{Calcium}

The relationship between calcium intake and hypertension is a complex and difficult one to isolate largely because of the interaction with other nutrients in the diets and difficulty in reliably collecting calcium intake data and important unmeasured confounding variables.

Despite an abundance of studies on the effect of dietary or supplemental calcium on blood pressure, the evidence on its benefit is inconclusive and remains controversial. An inverse relationship between dietary calcium intake and blood pressure has been reported in many studies [83-89]. Similarly, supplementation with $1000 \mathrm{mg}$ calcium/day has been demonstrated to lead to a decrease in blood pressure, although results were inconsistent and mainly among hypertensives [90-92]. In contrast, other studies report minimal to no effect of dietary calcium or supplementation on blood pressure [93-99]. In addition, contradictory results have been deduced from analysis of the same data as exemplified by the Nurses' Health Study $[85,94]$ and the NHANES $[89,100-103]$. The differences in study results may be explained by a variety of factors including heterogeneity of study participants, flaws in study design, limitations in measurement of blood pressure and calcium intake, short duration of studies, different analytical methods, as well as collinearity with other dietary factors such as magnesium, fiber, protein, and potassium.
Two meta-analyses assessed the relationship between dietary calcium supplementation and blood pressure. The authors found small reductions in SBP $(1-2 \mathrm{mmHg}$ ), and results were even smaller and insignificant for DBP $[104,105]$.

Similar results were reported in another meta-analysis by van Mierlo et al., effect on SBP of $-1.86 \mathrm{mmHg}$ (95\% CI, -2.91 to $-0.81 \mathrm{mmHg}$ ) and DBP of $-0.99 \mathrm{mmHg}(95 \% \mathrm{CI}$, -1.61 to $-0.37 \mathrm{mmHg}$ ), however, the impact on SBP was larger in people with relatively low calcium intake of $\leq 800 \mathrm{mg} /$ day [106]. A Cochrane review published in 2006 examined the efficacy of oral calcium supplementation as a treatment for hypertension. Only 13 randomized controlled trials with a total of 485 participants with at least 8 weeks duration were included. A statistically significant reduction in SBP $(-2.5 \mathrm{mmHg}, 95 \% \mathrm{CI},-4.5$ to $-0.6 \mathrm{mmHg})$, but not DBP ( $-0.8 \mathrm{mmHg}, 95 \% \mathrm{CI},-2.1$ to $0.4 \mathrm{mmHg}$ ), was found. Many of the trials were of poor quality, and the authors concluded that there was insufficient evidence to recommend calcium supplementation as a treatment for hypertension [107].

Currently, the evidence on the benefit of calcium supplementation in prevention or treatment of hypertension is weak; therefore, there is no justification to increase the intake of calcium above the recommended dietary allowance of $1000-1300 \mathrm{mg} /$ day based on age and gender. Foods rich in calcium are mainly dairy products (preferably low fat) such as milk, cheese, and yogurt.

Proposed mechanisms by which calcium intake regulates blood pressure include alteration in intracellular calcium which in turn affects vascular smooth muscle contraction [108], effect of calcium metabolism and regulatory hormones [109-111], increased natriuresis [112-114], and modulation of the function of the sympathetic nervous system [113]. Interestingly, among people consuming low levels of calcium in their diets, high salt intake is associated with higher blood pressure levels [115-117], and it is suggested that the hypertensive effect of a high sodium intake may be mitigated by increasing dietary calcium $[109,112,118,119]$. Resnick also published extensively on the interlinking of the reninaldosterone system, calcium regulation, and salt sensitivity in modulating blood pressure responses to salt loading, calcium supplementation, and calcium channel blockers [120-125]. He suggested that these models may provide a targeted approach to identifying and treating hypertensives with calcium supplementation or calcium channel blockers based on their serum renin level and salt sensitivity [126-128].

\section{Magnesium}

Magnesium deficiency has been found to result in increased blood pressure in single studies $[129,130]$. However, a metaanalysis looking at 29 observational studies points to a negative correlation between dietary magnesium intake and blood pressure [131].

The evidence of a causal association between magnesium supplementation and blood pressure reduction was weak in a meta-analysis including 12 randomized trials with followup ranging from 8 to 26 weeks [132]. In another meta-analysis with 20 studies, although a dose-response pattern was found, magnesium intake only resulted in a small overall reduction 
in blood pressure, a mean of $-0.6 \mathrm{mmHg}(95 \% \mathrm{CI},-2.2$ to $1.0 \mathrm{mmHg}$ ) for $\mathrm{SBP}$ and $-0.8 \mathrm{~mm} \mathrm{Hg}$ (95\% CI, -1.9 to $0.4 \mathrm{mmHg}$ ) for DBP [133].

On the basis of these data, the relationship between magnesium and hypertension seems inconsistent and not convincing. Currently, magnesium supplementation is not recommended as a means of hypertensive treatment.

\section{Alcohol}

A standard drink in the USA is equal to $14 \mathrm{~g}$ (6 ounces (oz)) of pure alcohol. This amount is present in $12 \mathrm{oz}$ of regular beer, $5 \mathrm{oz}$ of wine (12\% alcohol), $8 \mathrm{oz}$ of malt liquor, and $1.5 \mathrm{oz}$ of 80 -proof distilled spirits [134]. This serving size can be varied in different countries. In Britain or Australia, a unit of alcohol contains 8 to $10 \mathrm{~g}$ [135], while in Japan, a drink contains $19.75 \mathrm{~g}$ of alcohol. In this paper, we refer "a drink" to the US serving size. Otherwise, the amount of alcohol will be specified.

Moderate alcohol intake, defined as a maximum of 2 alcoholic drinks/day in men and 1 alcoholic drink/day in women and lighter-weight persons, is supported by the AHA 2006 scientific statement of hypertension management [28]. In a prospective cohort study involving 11,711 men with preexisting hypertension, individuals who consumed a moderate amount of alcohol tended to have a decreased risk of MI. After adjustment for measurement error, BMI and dietary variables, the hazard ratio for participants with MI per $12.5 \mathrm{~g} /$ day increment of alcohol intake was 0.68 (95\% CI, 0.46 to 1.00$)$ [136].

On the other hand, heavy drinking, generally referred to as any amount of alcohol use above the moderate level, is associated with a higher risk of hypertension in a dosedependent manner. This has been demonstrated in various populations: Japanese men [137], US women [138], and both men and women of different races [139]. The risk seems more pronounced in individuals with a smaller BMI [137]. In the INTERSALT study, compared to nondrinkers, men who drank 300-499 mL alcohol/week had higher SBP/DBP, on average $2.7 / 1.6 \mathrm{mmHg}$. Women who drank at least $300 \mathrm{~mL} /$ week had blood pressures higher by $3.9 / 3.1 \mathrm{mmHg}$ than nondrinkers [140]. Alcohol reduction was associated with a fall in blood pressure [141]. Available data supports that moderate alcohol consumption should be recommended as one of the components of hypertensive therapy.

\section{Fiber}

Fiber is the indigestible portion from plant-based food. How exactly fiber might affect blood pressure is not entirely understood. An inverse association between blood pressure and fiber intake has been described. Among 30,681 predominantly white US male health professionals, 40-75 years old, those with a fiber intake of less than $12 \mathrm{~g} /$ day were at higher risk of developing hypertension compared to those taking more than $24 \mathrm{~g} /$ day, relative risk 1.57 (95\% CI, 1.20 to 2.05) [88]. This relationship was independent of other nutrients including sodium, potassium, calcium, and magnesium. When the results of 24 randomized controlled trials were evaluated, fiber supplementation with an average dose of $11.5 \mathrm{~g} /$ day modestly reduced SBP by $-1.13 \mathrm{mmHg}(95 \%$ $\mathrm{CI},-2.49$ to $0.23 \mathrm{mmHg}$ ) and DBP by $-1.26 \mathrm{mmHg}(95 \% \mathrm{CI}$, -2.04 to $-0.48 \mathrm{mmHg}$ ). It seemed to have greater effect in populations with hypertension and in those older than 40 years of age [142]. Similarly, a large randomized trial failed to show a significant decrease in blood pressure with a high fiber diet [143]. According to the 2006 scientific statement from the AHA, there is insufficient evidence to recommend increased dietary fiber intake alone for the reduction of blood pressure [28].

\section{Omega-3 Polyunsaturated Fatty Acid (Fish Oil)}

Daily dietary fish consumption as a part of weight reduction regimens has shown benefits in blood pressure fall [144]. A body of evidence demonstrated the association between concentrated Omega-3 polyunsaturated fatty acid extracted from fish, hence usually known as "fish oil", and blood pressure reduction $[145,146]$. This effect might have a dose limit, as it was reported that fish oil did not change mean blood pressure in the subjects who ate fish three or more times a week as part of their usual diet, or in those who had a baseline concentration of plasma phospholipid omega-3 fatty acids above $175.1 \mathrm{mg} / \mathrm{L}$ [146]. Of note, these studies employed large doses of Omega-3 polyunsaturated fatty acid (at least $3 \mathrm{~g} /$ day), which raises a concern of safety and side effects in view of long-term use.

Mercury is a chemical element of which fish living in contaminated water can contain a high level in their body. Some cross-sectional studies have mentioned the possibility of increasing blood pressure caused by mercury. Would this go against the above findings of a positive correlation between daily fish meal and blood pressure reduction? Recently, two large prospective cohort studies on 6045 US men and women, do not support any effects of methylmercury on the risk of incident hypertension [147].

\section{Garlic}

Garlic is one of the most commonly used natural herbs. Its role in hypertension has also been explored by researchers. In patients with baseline elevated blood pressure, compared with placebo, garlic significantly reduced SBP by $16.3 \mathrm{mmHg}$ (95\% CI, 6.2 to $26.5 \mathrm{mmHg}$ ) and DBP by $9.3 \mathrm{mmHg}(95 \% \mathrm{CI}$, 5.3 to $13.3 \mathrm{mmHg}$ ) [148]. The effect was repeatedly illustrated in another meta-analysis [149]. Despite the potential advantage, the problem with nonstandardization in product preparation, formulas, and study heterogeneity does not allow a conclusive message regarding garlic use in hypertensive patients. It might be beneficial. However, how much, how long, and which products to use are not clearly identified.

\section{Products with Potential Harms}

10.1. Caffeine. Being the main ingredient in stimulant drinks, caffeine is found in coffee, tea, sodas, and many energy drinks. Acutely, caffeine can elevate blood pressure in nonhabitual 
caffeine users [150], whereas little to no effect was seen in habitual coffee drinkers [151, 152]. Chronic coffee drinkers who have hypertension might not need to change their habit based on the available data. Nevertheless, it can potentially be harmful for irregular coffee drinkers.

There is evidence that other ingredient than caffeine might be responsible for the stimulating effect of coffee on blood pressure. An increase in blood pressure was observed in decaffeinated coffee drinkers [153]. The use of caffeine alone did not exert an elevated blood pressure in healthy volunteers in a study [152].

10.2. Licorice. Licorice has been long used as a flavoring agent in chewing tobacco, candies, spices, and as a medical product in some gastrointestinal and upper respiratory disorders. It contains glycyrrhetinic acid which inhibits 11beta-hydroxysteroid dehydrogenase enzyme type 2 isoform, allowing cortisol to bind to the mineralocorticoid receptors creating a status of mineralocorticoid excess and subsequently blood pressure elevation. The use of licorice can be potentially dangerous in hypertensive individuals [154].

\section{Whole Dietary Pattern}

11.1. DASH Diet. The DASH diet is a diet rich in fruits and vegetables (4-5 servings/day) and low-fat dairy products (23 servings/day) and includes whole grains, poultry, fish, and nuts. This diet is rich in potassium, magnesium, calcium, dietary fiber, and protein and has reduced fat (total and saturated) and cholesterol $(<25 \%)$, red meat, sweets, and sugar-containing beverages.

Two controlled clinical trials established its efficacy in lowering blood pressure $[35,155]$. The initial DASH trial [155] enrolled 459 untreated participants with prehypertension and stage I hypertension and randomly assigned them to one of 3 groups (1) a control group which consumed a typical US diet which was low in fruits, vegetables, and dairy products and had a high fat content, (2) a diet rich in fruits and vegetables, or (3) the DASH diet sodium intake and body weight were held constant during the study period of eight weeks. Compared with the control group, blood pressure decreased by $5.5 / 3.0 \mathrm{mmHg}$ and $2.8 / 1.1 \mathrm{mmHg}$ in the DASH diet and fruits-and-vegetables diet, respectively. This reduction was higher among the subset of hypertensives at $11.4 / 5.5 \mathrm{mmHg}$ compared with $3.5 / 2.1 \mathrm{mmHg}$ for those without hypertension consuming the DASH diet. In addition, the reduction in blood pressure began within two weeks and was sustained for the next six weeks.

The DASH-sodium trial [35] was a crossover trial in which 412 subjects were randomized to either the control diet or DASH diet and 3 levels of sodium intake (low: $1.2 \mathrm{~g} /$ day, intermediate: $2.3 \mathrm{~g} / \mathrm{day}$, and high: $3.5 \mathrm{~g} /$ day) within each diet arm for four weeks. Participants had SBP between 120 to $159 \mathrm{mmHg}$ and DBP between 80 to $95 \mathrm{mmHg}$. Similar to the earlier study, the DASH diet significantly lowered blood pressure independent of sodium intake. With each diet, reducing the sodium intake significantly decreased blood pressure, and these effects persisted among those with and without hypertension, as well as across the different races and sex. The combination of the DASH diet and low sodium intake had the greatest impact, reducing SBP by 11.5/5.7 $\mathrm{mmHg}$ and 7.1/3.1 $\mathrm{mmHg}$ among hypertensives and those without hypertension, respectively, compared with the control diet and high sodium intake. The level of reduction among hypertensives is comparable to that obtained with drug monotherapy.

African Americans with hypertension derive the most benefit from the blood pressure lowering effect of the DASH diet [156], however they may be less likely to adhere to the diet $[157,158]$. Furthermore, the increase in blood pressure with aging can be reduced by adopting the DASH diet with sodium restriction $[36,159]$.

Other potential benefits of the DASH diet include reduction in cardiovascular morbidity [160, 161], mortality [162], CHF events $[163,164]$, and cardiovascular risks factors [165167] as well as prevention of type 2 diabetes [168].

The DASH and low sodium diet has been endorsed by professional organizations including the AHA [169], the JNC [1], the American Association of Clinical Endocrinologists [170], and the Canadian Hypertension Education Program [27] for the prevention and treatment of hypertension.

Barriers to compliance with the DASH diet include cost, availability, accessibility, lack of information, and cultural dietary preferences. The US Department of Health and Human Services published a guidebook, Your Guide to Lowering your Blood Pressure with DASH, which is a great resource to guide patients in preparation of meals in accordance with the DASH diet [171].

The PREMIER trial studied 810 adults with SBP ranging from 120 to $159 \mathrm{mmHg}$ and DBP 80 to $95 \mathrm{mmHg}$ [172]. Patients were divided into 3 intervention groups: one-time advice, "established" behavioral intervention based on the established recommendations, and "established plus DASH." Food was prepared by participants and they were followed up by telephone interview. The results showed that compared with the group receiving advice only, the 2 groups with behavioral interventions had significant decrease in the prevalence of hypertension and a higher percentage of optimal blood pressure at 6 month followup. However, there was no statistically significant difference between them.

11.2. Vegetarian Diet. Early observation has described lower blood pressure in vegetarians compared to patients on regular diets [173]. It seemed that sodium intake in vegetarian diet did not contribute a significant effect to blood pressure changes [174]. Recent studies also demonstrated that vegans do have lower SBP and DBP and less likely to use antihypertensive medications. In a study, for vegans, the odds ratio of hypertension compared with omnivores was 0.37 (95\% CI, 0.19 to 0.74 ) [175]. Vegetarian diet with increased intake of fruit and vegetables, polyunsaturated vegetable margarines, and oils, fiber, calcium, and magnesium and decreased intake of protein in mild untreated hypertensive patients resulted in a fall of $5 \mathrm{mmHg}$ in SBP. This diet improved blood pressure without a change in urinary sodium or potassium excretion or body weight [176]. Rouse and colleagues included 59 healthy normotensive patients in a randomized controlled 
study in which they were randomized to a control group (omnivorous diet) and one of 2 experimental groups (omnivorous and/or lacto-ovo-vegetarian diet). Mean SBP dropped by 5 to $6 \mathrm{mmHg}$ and DBP dropped by 2 to $3 \mathrm{mmHg}$ in the group on vegetarian diet after adjustment for age, obesity, heart rate, weight change, and blood pressure before dietary change. Blood pressure rose substantially in subjects who reverted to the omnivorous diet [177].

It appears that a vegetarian diet might reduce blood pressure by several factors: increased vegetables, fiber and fruit intake, low protein, and so forth.

\section{Conclusion}

Dietary modification has important therapeutic roles in blood pressure control. Strong evidence supports the recommendation of a diet containing high potassium, moderate alcohol, and high fiber intake. As a whole, a DASH pattern diet rich in fruits, vegetables, low-fat dairy products, whole grains, nuts, and fish with reduced amount of red meat, fat, sugar-sweetened food and beverages, and/or a vegetarian diet, which is also high in vegetables and fruits and low in animal protein should be considered. The use of pharmacological supplements to achieve these dietary goals is not advised. Sodium restriction is strongly recommended by professional organizations, however, this needs to be carefully interpreted and individualized given the evidence of associated potential harmful effects and its unequal efficacy in various patient populations. The recommendation is not quite definite in terms of increased intake of calcium, magnesium, fish oil, and garlic. Irregular coffee drinkers and licorice consumers face a possibility of inducing hypertension; thus, these habits need to be avoided in patients at risk.

Established nutrition recommendations are proven to be helpful in reducing blood pressure and thus hypertensionrelated complications and overall mortality. However, in view of the heterogeneity in risk factors, patient features, and pathogenesis of hypertension, the approach should be individualized and discussed in detail between the patient and their physician and/or dietician, based on the understanding of each patient's distinct disease characteristics.

The importance of dietary modification in hypertension management has been substantially studied for past decades with encouraging findings. Additional studies are warranted to further explore the role of these nutrient factors in preventing and treating this condition in special populations.

\section{References}

[1] A. V. Chobanian, G. L. Bakris, H. R. Black et al., "Seventh report of the joint national committee on prevention, detection, evaluation, and treatment of high blood pressure," Hypertension, vol. 42, no. 6, pp. 1206-1252, 2003.

[2] World Health Statistics, 2012, http://www.who.int/gho/publica tions/world_health_statistics/EN_WHS2012_Full.pdf.

[3] H. J. Adrogue and N. E. Madias, "Sodium and potassium in the pathogenesis of hypertension," The New England Journal of Medicine, vol. 356, no. 19, pp. 1966-1978, 2007.
[4] G. Rose, J. Stamler, R. Stamler et al., "Intersalt: an international study of electrolyte excretion and blood pressure. Results for 24 hour urinary sodium and potassium excretion," British Medical Journal, vol. 297, no. 6644, pp. 319-328, 1988.

[5] T. Kawasaki, C. S. Delea, F. C. Bartter, and H. Smith, "The effect of high-sodium and low-sodium intakes on blood pressure and other related variables in human subjects with idiopathic hypertension," American Journal of Medicine, vol. 64, no. 2, pp. 193-198, 1978.

[6] M. I. Koolen, E. Bussemaker-Verduyn Den Boer, and P. Van Brummelen, "Clinical biochemical and haemodynamic correlates of sodium sensitivity in essential hypertension," Journal of Hypertension, vol. 1, no. 2, pp. 21-23, 1983.

[7] F. C. Luft, C. E. Grim, L. R. Willis, J. T. Higgins Jr., and M. H. Weinberger, "Natriuretic response to saline infusion in normotensive and hypertensive man. The role of renin suppression in exaggerated natriuresis," Circulation, vol. 55, no. 5, pp. 779784, 1977.

[8] J. M. Sullivan and T. E. Ratts, "Sodium sensitivity in human subjects. Hemodynamic and hormonal correlates," Hypertension, vol. 11, no. 6, pp. 717-723, 1988.

[9] M. H. Weinberger, "Salt sensitivity of blood pressure in humans," Hypertension, vol. 27, no. 3, pp. 481-490, 1996.

[10] M. D. Lindheimer, R. C. Lalone, and N. G. Levinsky, "Evidence that an acute increase in glomerular filtration has little effect on sodium excretion in the dog unless extracellular volume is expanded," Journal of Clinical Investigation, vol. 46, no. 2, pp. 256-265, 1967.

[11] F. C. Luft, J. Z. Miller, C. E. Grim et al., "Salt sensitivity and resistance of blood pressure. Age and race as factors in physiological responses," Hypertension, vol. 17, no. 1, supplement, pp. I102-I108, 1991.

[12] B. L. Rodriguez, D. R. Labarthe, B. Huang, and J. Lopez-Gomez, "Rise of blood pressure with age: new evidence of population differences," Hypertension, vol. 24, no. 6, pp. 779-785, 1994.

[13] L. A. Sechi, "Mechanisms of insulin resistance in rat models of hypertension and their relationships with salt sensitivity," Journal of Hypertension, vol. 17, no. 9, pp. 1229-1237, 1999.

[14] C. Ferri, C. Bellini, G. Desideri et al., "Clustering of endothelial markers of vascular damage in human salt- sensitive hypertension: influence of dietary sodium load and depletion," Hypertension, vol. 32, no. 5, pp. 862-868, 1998.

[15] R. Bigazzi, S. Bianchi, D. Baldari, G. Sgherri, G. Baldari, and V. M. Campese, "Microalbuminuria in salt-sensitive patients: a marker for renal and cardiovascular risk factors," Hypertension, vol. 23, no. 2, pp. 195-199, 1994.

[16] V. M. Campese, M. Parise, F. Karubian, and R. Bigazzi, "Abnormal renal hemodynamics in black salt-sensitive patients with hypertension," Hypertension, vol. 18, no. 6, pp. 805-812, 1991.

[17] J. H. Laragh and L. M. Resnick, "Recognizing and treating two types of long-term vasoconstriction in hypertension," Kidney International, vol. 34, no. 25, pp. S162-S174, 1988.

[18] K. Ishibashi, T. Oshima, H. Matsuura et al., "Effects of age and sex on sodium chloride sensitivity: association with plasma renin activity," Clinical Nephrology, vol. 42, no. 6, pp. 376-380, 1994.

[19] L. Torielli, S. Tivodar, R. C. Montella et al., " $\alpha$-Adducin mutations increase $\mathrm{Na} / \mathrm{K}$ pump activity in renal cells by affecting constitutive endocytosis: implications for tubular Na reabsorption," American Journal of Physiology, vol. 295, no. 2, pp. F478-F487, 2008. 
[20] K. Stenström, H. Takemori, G. Bianchi, A. I. Katz, and A. M. Bertorello, "Blocking the salt-inducible kinase 1 network prevents the increases in cell sodium transport caused by a hypertension-linked mutation in human $\alpha$-adducin Calmodulin Cytoskeleton $\mathrm{Na}^{+} \mathrm{K}^{+}$-AtPase Sodium reabsorption," Journal of Hypertension, vol. 27, no. 12, pp. 2452-2457, 2009.

[21] H. Sanada, J. Yatabe, S. Midorikawa et al., "Single-nucleotide polymorphisms for diagnosis of salt-sensitive hypertension," Clinical Chemistry, vol. 52, no. 3, pp. 352-360, 2006.

[22] C. E. Gariepy, T. Ohuchi, S. C. Williams, J. A. Richardson, and M. Yanagisawa, "Salt-sensitive hypertension in endothelin-B receptor-deficient rats," Journal of Clinical Investigation, vol. 105, no. 7, pp. 925-933, 2000.

[23] A. De La Sierra, M. M. Lluch, J. C. Pare et al., "Increased left ventricular mass in salt-sensitive hypertensive patients," Journal of Human Hypertension, vol. 10, no. 12, pp. 795-799, 1996.

[24] A. Morimoto, T. Uzu, T. Fujii et al., "Sodium sensitivity and cardiovascular events in patients with essential hypertension," The Lancet, vol. 350, no. 9093, pp. 1734-1737, 1997.

[25] M. H. Weinberger, N. S. Fineberg, S. E. Fineberg, and M. Weinberger, "Salt sensitivity, pulse pressure, and death in normal and hypertensive humans," Hypertension, vol. 37, no. 2, pp. 429-432, 2001.

[26] WHO, "Diet, Nutrition and the Prevention of Chronic Diseases. Technical Report Series 916," 2003, http://whqlibdoc.who .int/trs/who_trs_916.pdf.

[27] N. A. Khan, B. Hemmelgarn, R. J. Herman, C. M. Bell, J. L. Mahon, L. A. Leiter et al., "The 2009 Canadian Hypertension Education Program recommendations for the management of hypertension: part 2-therapy," Canadian Journal of Cardiology, vol. 25, no. 5, pp. 287-298, 2009.

[28] L. J. Appel, M. W. Brands, S. R. Daniels, N. Karanja, P. J. Elmer, and F. M. Sacks, "Dietary approaches to prevent and treat hypertension: a scientific statement from the American Heart Association," Hypertension, vol. 47, no. 2, pp. 296-308, 2006.

[29] M. H. Alderman, "Reducing dietary sodium: the case for caution," Journal of the American Medical Association, vol. 303, no. 5, pp. 448-449, 2010.

[30] D. A. McCarron, "The dietary guideline for sodium: should we shake it up? Yes!," American Journal of Clinical Nutrition, vol. 71, no. 5, pp. 1013-1019, 2000.

[31] J. A. Cutler, "Effects of weight loss and sodium reduction intervention on blood pressure and hypertension incidence in overweight people with high-normal blood pressure: the trials of hypertension prevention, phase II," Archives of Internal Medicine, vol. 157, no. 6, pp. 657-667, 1997.

[32] H. G. Langford, M. D. Blaufox, and A. Oberman, "Dietary therapy slows the return of hypertension after stopping prolonged medication," Journal of the American Medical Association, vol. 253, no. 5, pp. 657-664, 1985.

[33] P. K. Whelton, L. J. Appel, M. A. Espeland et al., "Sodium reduction and weight loss in the treatment of hypertension in older persons: a randomized controlled trial of nonpharmacologic interventions in the elderly (TONE)," Journal of the American Medical Association, vol. 279, no. 11, pp. 839-846, 1998.

[34] F. J. He and G. A. MacGregor, "Effect of modest salt reduction on blood pressure: a meta-analysis of randomized trials. Implications for public health," Journal of Human Hypertension, vol. 16, no. 11, pp. 761-770, 2002.

[35] F. M. Sacks, L. P. Svetkey, W. M. Vollmer et al., "Effects on blood pressure of reduced dietary sodium and the dietary approaches to stop hypertension (dash) diet," The New England Journal of Medicine, vol. 344, no. 1, pp. 3-10, 2001.

[36] G. A. Bray, W. M. Vollmer, F. M. Sacks, E. Obarzanek, L. P. Svetkey, and L. J. Appel, "A further subgroup analysis of the effects of the DASH diet and three dietary sodium levels on blood pressure: results of the DASH-sodium trial," American Journal of Cardiology, vol. 94, no. 2, pp. 222-227, 2004.

[37] N. R. Cook, J. A. Cutler, E. Obarzanek et al., "Long term effects of dietary sodium reduction on cardiovascular disease outcomes: observational follow-up of the trials of hypertension prevention (TOHP)," British Medical Journal, vol. 334, no. 7599, pp. 885-888, 2007.

[38] J. Tuomilehto, P. Jousilahti, D. Rastenyte et al., "Urinary sodium excretion and cardiovascular mortality in Finland: a prospective study," The Lancet, vol. 357, no. 9259, pp. 848-851, 2001.

[39] P. Strazzullo, L. D’Elia, N. B. Kandala, and F. P. Cappuccio, "Salt intake, stroke, and cardiovascular disease: meta-analysis of prospective studies," British Medical Journal, vol. 339, Article ID b4567, 2009.

[40] M. H. Alderman, S. Madhavan, H. Cohen et al., "Low urinary sodium is associated with greater risk of myocardial infarction among treated hypertensive men," Hypertension, vol. 25, no. 6, pp. 1144-1152, 1995.

[41] M. H. Alderman, H. Cohen, and S. Madhavan, "Dietary sodium intake and mortality: the National Health and Nutrition Examination Survey (NHANES I)," The Lancet, vol. 351, no. 9105, pp. 781-785, 1998.

[42] K. Stolarz-Skrzypek, T. Kuznetsova, L. Thijs et al., "Fatal and nonfatal outcomes, incidence of hypertension, and blood pressure changes in relation to urinary sodium excretion," Journal of the American Medical Association, vol. 305, no. 17, pp. 1777-1785, 2011.

[43] G. Jürgens and N. A. Graudal, "Effects of low sodium diet versus high sodium diet on blood pressure, renin, aldosterone, catecholamines, cholesterols, and triglyceride," Cochrane Database of Systematic Reviews, no. 1, Article ID CD004022, 2003.

[44] A. B. Weder and B. M. Egan, "Potential deleterious impact of dietary salt restriction on cardiovascular risk factors," Klinische Wochenschrift, vol. 69, supplement 25, pp. 45-50, 1991.

[45] T. Iwaoka, T. Umeda, M. Ohno et al., "The effect of low and high $\mathrm{NaCl}$ diets on oral glucose tolerance," Klinische Wochenschrift, vol. 66, no. 16, pp. 724-728, 1988.

[46] F. Masugi, T. Ogihara, K. Hashizume, T. Hasegawa, K. Sakaguchi, and Y. Kumahara, "Changes in plasma lipids and uric acid with sodium loading and sodium depletion in patients with essential hypertension," Journal of Human Hypertension, vol. 1, no. 4, pp. 293-298, 1988.

[47] S. Paterna, P. Gaspare, S. Fasullo, F. M. Sarullo, and P. Di Pasquale, "Normal-sodium diet compared with low-sodium diet in compensated congestive heart failure: is sodium an old enemy or a new friend?" Clinical Science, vol. 114, no. 3-4, pp. 221-230, 2008.

[48] S. Paterna, G. Parrinello, S. Cannizzaro et al., "Medium term effects of different dosage of diuretic, sodium, and fluid administration on neurohormonal and clinical outcome in patients with recently compensated heart failure," American Journal of Cardiology, vol. 103, no. 1, pp. 93-102, 2009.

[49] M. C. Thomas, J. Moran, C. Forsblom et al., "The association between dietary sodium intake, ESRD, and all-cause mortality in patients with type 1 diabetes," Diabetes Care, vol. 34, no. 4, pp. 861-866, 2011. 
[50] E. I. Ekinci, S. Clarke, M. C. Thomas et al., "Dietary salt intake and mortality in patients with type 2 diabetes," Diabetes Care, vol. 34, no. 3, pp. 703-709, 2011.

[51] A. De La Sierra, M. Del Mar Lluch, A. Coca et al., "Assessment of salt sensitivity in essential hypertension by 24 -h ambulatory blood pressure monitoring," American Journal of Hypertension, vol. 8, no. 10, pp. 970-977, 1995.

[52] F. Galletti, I. Ferrara, F. Stinga, R. Iacone, F. Noviello, and P. Strazzullo, "Evaluation of a rapid protocol for the assessment of salt sensitivity against the blood pressure response to dietary sodium chloride restriction," American Journal of Hypertension, vol. 10, no. 4, pp. 462-466, 1997.

[53] C. L. Laffer and F. Elijovich, "Essential hypertension of Caribbean hispanics: sodium, renin, and response to therapy," Journal of Clinical Hypertension, vol. 4, no. 4, pp. 266-273, 2002.

[54] "Fludrocortisone's Test in Salt Sensitivity", 2012, http://clinical trials.gov/ct2/show/NCT01453959.

[55] WHO, "Guideline: sodium intake for adults and children," World Health Organization (WHO), 2012, http://www.who.int/ nutrition/publications/guidelines/sodium_intake_printversion .pdf.

[56] K. T. Khaw and E. Barrett-Connor, "Dietary potassium and blood pressure in a population," American Journal of Clinical Nutrition, vol. 39, no. 6, pp. 963-968, 1984.

[57] J. M. Geleijnse, J. C. M. Witteman, J. H. Den Breeijen et al., "Dietary electrolyte intake and blood pressure in older subjects: the Rotterdam Study," Journal of Hypertension, vol. 14, no. 6, pp. 737-741, 1996.

[58] G. G. Krishna and S. C. Kapoor, "Potassium depletion exacerbates essential hypertension," Annals of Internal Medicine, vol. 115 , no. 2, pp. 77-83, 1991.

[59] F. P. Cappuccio and G. A. MacGregor, "Does potassium supplementation lower blood pressure? A meta-analysis of published trials," Journal of Hypertension, vol. 9, no. 5, pp. 465-473, 1991.

[60] J. M. Geleijnse, F. J. Kok, and D. E. Grobbee, "Blood pressure response to changes in sodium and potassium intake: a metaregression analysis of randomised trials," Journal of Human Hypertension, vol. 17, no. 7, pp. 471-480, 2003.

[61] H. O. Dickinson, D. J. Nicolson, F. Campbell, F. R. Beyer, and J. Mason, "Potassium supplementation for the management of primary hypertension in adults," Cochrane Database of Systematic Reviews, vol. 3, Article ID CD004641, 2006.

[62] P. K. Whelton, J. He, J. A. Cutler et al., "Effects of oral potassium on blood pressure: meta-analysis of randomized controlled clinical trials," Journal of the American Medical Association, vol. 277, no. 20, pp. 1624-1632, 1997.

[63] P. C. W. Van Den Hoogen, E. J. M. Feskens, N. J. D. Nagelkerke, A. Menotti, A. Nissinen, and D. Kromhout, "The relation between blood pressure and mortality due to coronary heart disease among men in different parts of the world," The New England Journal of Medicine, vol. 342, no. 1, pp. 1-8, 2000.

[64] A. Rodgers, S. MacMahon, G. Gamble, J. Slattery, P. Sandercock, and C. Warlow, "Blood pressure and risk of stroke in patients with cerebrovascular disease," British Medical Journal, vol. 313, no. 7050 , article $147,1996$.

[65] P. Rashid, J. Leonardi-Bee, and P. Bath, "Blood pressure reduction and secondary prevention of stroke and other vascular events: a systematic review," Stroke, vol. 34, no. 11, pp. 2741-2748, 2003.

[66] Q. Yang, T. Liu, E. V. Kuklina et al., "Sodium and potassium intake and mortality among US adults: prospective data from the third national health and nutrition examination survey," Archives of Internal Medicine, vol. 171, no. 13, pp. 1183-1191, 2011.

[67] K. T. Khaw and E. Barrett-Connor, "Dietary of potassium and stroke-associated mortality. A 12-year prospective population study," The New England Journal of Medicine, vol. 316, no. 5, pp. 235-240, 1987.

[68] M. Brandis, J. Keyes, and E. E. Windhager, "Potassium-induced inhibition of proximal tubular fluid reabsorption in rats," The American Journal of Physiology, vol. 222, no. 2, pp. 421-427, 1972.

[69] A. J. Vander, "Direct effects of potassium on renin secretion and renal function," The American Journal of Physiology, vol. 219, no. 2, pp. 455-459, 1970.

[70] M. B. Pamnani, X. Chen, F. J. Haddy, J. F. Schooley, and Z. Mo, "Mechanism of antihypertensive effect of dietary potassium in experimental volume expanded hypertension in rats," Clinical and Experimental Hypertension, vol. 22, no. 6, pp. 555-569, 2000.

[71] G. Edwards, K. A. Dora, M. J. Gardener, C. J. Garland, and A. H. Weston, " $\mathrm{K}^{+}$is an endothelium-derived hyperpolarizing factor in rat arteries," Nature, vol. 396, no. 6708, pp. 269-272, 1998.

[72] W. Kuschinsky, M. Wahl, O. Bosse, and K. Thurau, "Perivascular potassium and $\mathrm{pH}$ as determinants of local pial arterial diameter in cats. A microapplication study," Circulation Research, vol. 31, no. 2, pp. 240-247, 1972.

[73] M. S. Zhou, Y. Nishida, H. Yoneyama, Q. H. Chen, and H. Kosaka, "Potassium supplementation increases sodium excretion and nitric oxide production in hypertensive Dahl rats," Clinical and Experimental Hypertension, vol. 21, no. 8, pp. 13971411, 1999.

[74] H. J. Knot, P. A. Zimmermann, and M. T. Nelson, "Extracellular $\mathrm{K}^{+}$-induced hyperpolarizations and dilatations of rat coronary and cerebral arteries involve inward rectifier $\mathrm{K}^{+}$channels," Journal of Physiology, vol. 492, no. 2, pp. 419-430, 1996.

[75] M. Kido, K. Ando, M. L. Onozato et al., "Protective effect of dietary potassium against vascular injury in salt-sensitive hypertension," Hypertension, vol. 51, no. 2, pp. 225-231, 2008.

[76] T. Ishimitsu, L. Tobian, K. Sugimoto, and T. Everson, "High potassium diets reduce vascular and plasma lipid peroxides in stroke-prone spontaneously hypertensive rats," Clinical and Experimental Hypertension, vol. 18, no. 5, pp. 659-673, 1996.

[77] National Research Council, Dietary Reference Intakes for Water, Potassium, Sodium, Chloride, and Sulfate, The National Academies Press, Washington, DC, USA, 2005.

[78] J. A. Whitworth, "2003 World Health Organization (WHO)/ International Society of Hypertension (ISH) statement on management of hypertension," Journal of Hypertension, vol. 21, no. 11, pp. 1983-1992, 2003.

[79] M. E. Cogswell, Z. Zhang, A. L. Carriquiry, J. P. Gunn, E. V. Kuklina, S. H. Saydah et al., "Sodium and potassium intakes among US adults: NHANES, 2003-2008," American Journal of Clinical Nutrition, vol. 96, no. 3, pp. 647-657, 2012.

[80] S. Männistö, M. L. Ovaskainen, and L. Valsta, The National Findiet 2002 Study, Publications of the National Public Health Institute, 2003.

[81] L. I. K. Henderson, J. Gregory, C. J. Bates et al., The National Diet \& Nutrition Survey: Adults Aged 19 to 64 Years, vol. 3 of Vitamin and Mineral intake and Urinary Analytes, Food Standards Agency and the Departments of Health by the Social Survey Division of the Office for National Statistics and Medical Research Council Human Nutrition Research, London, UK, 2003. 
[82] H. G. Tian, G. Hu, Q. N. Dong et al., "Dietary sodium and potassium, socioeconomic status and blood pressure in a Chinese population," Appetite, vol. 26, no. 3, pp. 235-246, 1996.

[83] D. Reed, D. McGee, K. Yano, and J. Hankin, "Diet, blood pressure, and multicollinearity," Hypertension, vol. 7, no. 3, pp. 405-410, 1985.

[84] J. H. Dwyer, L. Li, K. M. Dwyer, L. R. Curtin, and M. Feinleib, "Dietary calcium, alcohol, and incidence of treated hypertension in the NHANES I epidemiologic follow-up study," American Journal of Epidemiology, vol. 144, no. 9, pp. 828-838, 1996.

[85] J. C. M. Witteman, W. C. Willett, M. J. Stampfer et al., "A prospective study of nutritional factors and hypertension among US women," Circulation, vol. 80, no. 5, pp. 1320-1327, 1989.

[86] L. Wang, J. E. Manson, J. E. Buring, I. M. Lee, and H. D. Sesso, "Dietary intake of dairy products, calcium, and vitamin D and the risk of hypertension in middle-aged and older women," Hypertension, vol. 51, no. 4, pp. 1073-1079, 2008.

[87] J. A. Cutler and E. Brittain, "Calcium and blood pressure. An epidemiologic perspective," American Journal of Hypertension, vol. 3, no. 8, pp. 137S-146S, 1990.

[88] A. Ascherio, E. B. Rimm, E. L. Giovannucci et al., "A prospective study of nutritional factors and hypertension among US men," Circulation, vol. 86, no. 5, pp. 1475-1484, 1992.

[89] D. A. McCarron, C. D. Morris, H. J. Henry, and J. L. Stanton, "Blood pressure and nutrient intake in the United States," Science, vol. 224, no. 4656, pp. 1392-1398, 1984.

[90] J. M. Belizan, J. Villar, and O. Pineda, "Reduction of blood pressure with calcium supplementation in young adults," Journal of the American Medical Association, vol. 249, no. 9, pp. 1161-1165, 1983.

[91] D. A. McCarron and C. D. Morris, "Blood pressure response to oral calcium in persons with mild to moderate hypertension: a randomized, double-blind, placebo-controlled, crossover trial," Annals of Internal Medicine, vol. 103, no. 6, pp. 825-831, 1985.

[92] D. E. Grobbee and A. Hofman, "Effect of calcium supplementation on diastolic blood pressure in young people with mild hypertension," The Lancet, vol. 2, no. 8509, pp. 703-706, 1986.

[93] P. Strazzullo, A. Siani, and S. Guglielmi, "Controlled trial of long-term oral calcium supplementation in essential hypertension," Hypertension, vol. 8, no. 11, pp. 1084-1088, 1986.

[94] A. Ascherio, C. Hennekens, W. C. Willett et al., "Prospective study of nutritional factors, blood pressure, and hypertension among US women," Hypertension, vol. 27, no. 5, pp. 1065-1072, 1996.

[95] I. J. Davis, C. Grim, K. Dwyer, L. Nicholson, and J. Dwyer, “The effects of calcium supplementation on ambulatory blood pressure in african-american adolescents," Journal of the National Medical Association, vol. 88, no. 12, pp. 774-778, 1996.

[96] F. P. Cappuccio, N. D. Markandu, and D. R. J. Singer, "Does oral calcium supplementation lower high blood pressure? A double blind study," Journal of Hypertension, vol. 5, no. 1, pp. 67-71, 1987.

[97] F. P. Cappuccio, A. Siani, and P. Strazzullo, "Oral calcium supplementation and blood pressure: an overview of randomized controlled trials," Journal of Hypertension, vol. 7, no. 12, pp. 941946, 1989.

[98] L. E. Griffith, G. H. Guyatt, R. J. Cook, H. C. Bucher, and D. J. Cook, "The influence of dietary and nondietary calcium supplementation on blood pressure: an updated metaanalysis of randomized controlled trials," American Journal of Hypertension, vol. 12, no. 1, pp. 84-92, 1999.
[99] "The effects of nonpharmacologic interventions on blood pressure of persons with high normal levels. Results of the trials of hypertension prevention, phase I," Journal of the American Medical Association, vol. 267, no. 9, pp. 1213-1220, 1992.

[100] H. W. Gruchow, K. A. Sobocinski, and J. J. Barboriak, "Alcohol, nutrient intake, and hypertension in US adults," Journal of the American Medical Association, vol. 253, no. 11, pp. 1567-1570, 1985.

[101] M. Feinleib, C. Lenfant, and S. A. Miller, "Hypertension and calcium," Science, vol. 226, no. 4673, pp. 386-393, 1984.

[102] C. Sempos, R. Cooper, and M. G. Kovar, "Dietary calcium and blood pressure in National Health and Nutrition Examination Surveys I and II," Hypertension, vol. 8, no. 11, pp. 1067-1074, 1986.

[103] W. R. Harlan, A. L. Hull, R. L. Schmouder, J. R. Landis, F. E. Thompson, and F. A. Larkin, "Blood pressure and nutrition in adults. The National Health and Nutrition Examination Survey," American Journal of Epidemiology, vol. 120, no. 1, pp. 17-28, 1984.

[104] P. S. Allender, J. A. Cutler, D. Follmann, F. P. Cappuccio, J. Pryer, and P. Elliott, "Dietary calcium and blood pressure: a meta-analysis of randomized clinical trials," Annals of Internal Medicine, vol. 124, no. 9, pp. 825-831, 1996.

[105] H. C. Bucher, R. J. Cook, G. H. Guyatt et al., "Effects of dietary calcium supplementation on blood pressure: a meta-analysis of randomized controlled trials," Journal of the American Medical Association, vol. 275, no. 13, pp. 1016-1022, 1996.

[106] L. A. J. van Mierlo, L. R. Arends, M. T. Streppel et al., "Blood pressure response to calcium supplementation: a meta-analysis of randomized controlled trials," Journal of Human Hypertension, vol. 20, no. 8, pp. 571-580, 2006.

[107] H. O. Dickinson, D. J. Nicolson, J. V. Cook et al., "Calcium supplementation for the management of primary hypertension in adults," Cochrane Database of Systematic Reviews, no. 2, Article ID CD004639, 2006.

[108] M. C. Houston and K. J. Harper, "Potassium, magnesium, and calcium: their role in both the cause and treatment of hypertension," Journal of Clinical Hypertension, vol. 10, no. 7, pp. 3-11, 2008.

[109] D. A. McCarron, "Role of adequate dietary calcium intake in the prevention and management of salt-sensitive hypertension," American Journal of Clinical Nutrition, vol. 65, no. 2, pp. 712S716S, 1997.

[110] H. Yamakawa, H. Suzuki, M. Nakamura, Y. Ohno, and T. Saruta, "Disturbed calcium metabolism in offspring of hypertensive parents," Hypertension, vol. 19, no. 6, pp. 528-534, 1992.

[111] P. Lijnen and V. Petrov, "Dietary calcium, blood pressure and cell membrane cation transport systems in males," Journal of Hypertension, vol. 13, no. 8, pp. 875-882, 1995.

[112] K. Saito, H. Sano, Y. Furuta, and H. Fukuzaki, "Effect of oral calcium on blood pressure response in salt-loaded borderline hypertensive patients," Hypertension, vol. 13, no. 3, pp. 219-226, 1989.

[113] D. C. Hatton and D. A. McCarron, "Dietary calcium and blood pressure in experimental models of hypertension: a review," Hypertension, vol. 23, no. 4, pp. 513-530, 1994.

[114] J. R. Sowers, M. B. Zemel, P. C. Zemel, and P. R. Standley, "Calcium metabolism and dietary calcium in salt sensitive hypertension," American Journal of Hypertension, vol. 4, no. 6, pp. 557-563, 1991.

[115] P. Hamet, E. Mongeau, J. Lambert et al., "Interactions among calcium, sodium, and alcohol intake as determinants of blood 
pressure," Hypertension, vol. 17, no. 1, supplement, pp. I150-I154, 1991.

[116] P. Hamet, M. Daignault-Gelinas, J. Lambert et al., "Epidemiological evidence of an interaction between calcium and sodium intake impacting on blood pressure. A Montreal Study," American Journal of Hypertension, vol. 5, no. 6, pp. 378-385, 1992.

[117] H. W. Gruchow, K. A. Sobocinski, and J. J. Barboriak, "Calcium intake and the relationship of dietary sodium and potassium to blood pressure," American Journal of Clinical Nutrition, vol. 48, no. 6, pp. 1463-1470, 1988.

[118] T. A. Kotchen and D. A. McCarron, "Dietary electrolytes and blood pressure: a statement for healthcare professionals from the American Heart Association Nutrition Committee," Circulation, vol. 98, no. 6, pp. 613-617, 1998.

[119] M. H. Weinberger, U. L. Wagner, and N. S. Fineberg, “The blood pressure effects of calcium supplementation in humans of known sodium responsiveness," American Journal of Hypertension, vol. 6, no. 9, pp. 799-805, 1993.

[120] L. M. Resnick, F. B. Muller, and J. H. Laragh, "Calciumregulating hormones in essential hypertension: relation to plasma renin activity and sodium metabolism," Annals of Internal Medicine, vol. 105, no. 5, pp. 649-654, 1986.

[121] L. M. Resnick, J. P. Nicholson, and J. H. Laragh, "Calcium metabolism in essential hypertension: relationship to altered renin system activity," Federation Proceedings, vol. 45, no. 12, pp. 2739-2745, 1986.

[122] L. M. Resnick and J. H. Laragh, "Renin, calcium metabolism and the pathophysiologic basis of antihypertensive therapy," American Journal of Cardiology, vol. 56, no. 16, pp. H68-H74, 1985.

[123] L. M. Resnick, J. P. Nicholson, and J. H. Laragh, "Alterations in calcium metabolism mediate dietary salt sensitivity in essential hypertension," Transactions of the Association of American Physicians, vol. 98, pp. 313-321, 1985.

[124] L. M. Resnick, J. H. Laragh, J. E. Sealey, and M. H. Alderman, "Divalent cations in essential hypertension. Relations between serum ionized calcium, magnesium, and plasma renin activity," The New England Journal of Medicine, vol. 309, no. 15, pp. 888891, 1983.

[125] L. M. Resnick and J. H. Laragh, "The significance of calcium and calcium channel blockade in essential hypertension," Journal of Hypertension, vol. 3, no. 3, pp. S541-S544, 1985.

[126] L. Resnick, "Calcium metabolism, renin activity, and the antihypertensive effects of calcium channel blockade," The American Journal of Medicine, vol. 81, no. 6, pp. 6-14, 1986.

[127] L. M. Resnick, "The effects of sodium and calcium in clinical hypertension: mediating role of vitamin D metabolism," Advances in Second Messenger and Phosphoprotein Research, vol. 24, pp. 535-541, 1990.

[128] L. M. Resnick, "Alterations of dietary calcium intake as a therapeutic modality in essential hypertension," Canadian Journal of Physiology and Pharmacology, vol. 64, no. 6, pp. 803-807, 1986.

[129] B. M. Altura, B. T. Altura, and A. Gebrewold, "Magnesium deficiency and hypertension: correlation between magnesiumdeficient diets and microcirculatory changes in situ," Science, vol. 223, no. 4642, pp. 1315-1317, 1984.

[130] J. Ma, A. R. Folsom, S. L. Melnick et al., "Associations of serum and dietary magnesium with cardiovascular disease, hypertension, diabetes, insulin, and carotid arterial wall thickness: the aric study," Journal of Clinical Epidemiology, vol. 48, no. 7, pp. 927-940, 1995.
[131] S. Mizushima, F. P. Cappuccio, R. Nichols, and P. Elliott, "Dietary magnesium intake and blood pressure: a qualitative overview of the observational studies," Journal of Human Hypertension, vol. 12, no. 7, pp. 447-453, 1998.

[132] H. O. Dickinson, D. J. Nicolson, F. Campbell et al., "Magnesium supplementation for the management of essential hypertension in adults," Cochrane Database of Systematic Reviews, vol. 3, Article ID CD004640, 2006.

[133] S. H. A. Jee, E. R. Miller, E. Guallar, V. K. Singh, L. J. Appel, and M. J. Klag, "The effect of magnesium supplementation on blood pressure: a meta-analysis of randomized clinical trials," American Journal of Hypertension, vol. 15, no. 8, pp. 691-696, 2002.

[134] Centers for Disease Control and Prevention, 2012, http://www .cdc.gov/alcohol/faqs.htm\#standDrink.

[135] "Australian Government Department of Health and Aging," 2012, http://www.alcohol.gov.au/internet/alcohol/publishing .nsf/Content/standard.

[136] J. W. J. Beulens, E. B. Rimm, A. Ascherio, D. Spiegelman, H. F. J. Hendriks, and K. J. Mukamal, "Alcohol consumption and risk for coronary heart disease among men with hypertension," Annals of Internal Medicine, vol. 146, no. 1, pp. 10-19, 2007.

[137] N. Nakanishi, H. Yoshida, K. Nakamura, K. Suzuki, and K. Tatara, "Alcohol consumption and risk for hypertension in middle-aged Japanese men," Journal of Hypertension, vol. 19, no. 5, pp. 851-855, 2001.

[138] R. Thadhani, C. A. Camargo, M. J. Stampfer, G. C. Curhan, W. C. Willett, and E. B. Rimm, "Prospective study of moderate alcohol consumption and risk of hypertension in young women," Archives of Internal Medicine, vol. 162, no. 5, pp. 569-574, 2002.

[139] F. D. Fuchs, L. E. Chambless, P. K. Whelton, F. J. Nieto, and G. Heiss, "Alcohol consumption and the incidence of hypertension: the Atherosclerosis Risk in Communities Study," Hypertension, vol. 37, no. 5, pp. 1242-1250, 2001.

[140] M. G. Marmot, P. Elliott, M. J. Shipley et al., "Alcohol and blood pressure: the INTERSALT Study," British Medical Journal, vol. 308, no. 6939, pp. 1263-1267, 1994.

[141] X. Xin, J. He, M. G. Frontini, L. G. Ogden, O. I. Motsamai, and P. K. Whelton, "Effects of alcohol reduction on blood pressure: a meta-analysis of randomized controlled trials," Hypertension, vol. 38, no. 5, pp. 1112-1117, 2001.

[142] M. T. Streppel, L. R. Arends, P. Van't Veer, D. E. Grobbee, and J. M. Geleijnse, "Dietary fiber and blood pressure: a meta-analysis of randomized placebo-controlled trials," Archives of Internal Medicine, vol. 165, no. 2, pp. 150-156, 2005.

[143] J. He, R. H. Streiffer, P. Muntner, M. A. Krousel-Wood, and P. K. Whelton, "Effect of dietary fiber intake on blood pressure: a randomized, double-blind, placebo-controlled trial," Journal of Hypertension, vol. 22, no. 1, pp. 73-80, 2004.

[144] T. A. Mori, V. Burke, I. B. Puddey, J. E. Shaw, and L. J. Beilin, "Effect of fish diets and weight loss on serum leptin concentration in overweight, treated-hypertensive subjects," Journal of Hypertension, vol. 22, no. 10, pp. 1983-1990, 2004.

[145] K. H. Bonaa, K. S. Bjerve, B. Straume, I. T. Gram, and D. Thelle, "Effect of eicosapentaenoic and docosahexaenoic acids on blood pressure in hypertension. A population-based intervention trial from the Tromso study," The New England Journal of Medicine, vol. 322, no. 12, pp. 795-801, 1990.

[146] H. R. Knapp and G. A. Fitzgerald, "The antihypertensive effects of fish oil. A controlled study of polyunsaturated fatty acid supplements in essential hypertension," The New England Journal of Medicine, vol. 320, no. 16, pp. 1037-1043, 1989. 
[147] D. Mozaffarian, P. Shi, J. S. Morris, P. Grandjean, D. S. Siscovick, D. Spiegelman et al., "Mercury exposure and risk of hypertension in US men and women in 2 prospective cohorts," Hypertension, vol. 60, no. 3, pp. 645-652, 2012.

[148] K. M. Reinhart, C. I. Coleman, C. Teevan, P. Vachhani, and C. M. White, "Effects of garlic on blood pressure in patients with and without systolic hypertension: a meta-analysis," Annals of Pharmacotherapy, vol. 42, no. 12, pp. 1766-1771, 2008.

[149] K. Ried, O. R. Frank, N. P. Stocks, P. Fakler, and T. Sullivan, "Effect of garlic on blood pressure: a systematic review and meta-analysis," BMC Cardiovascular Disorders, vol. 8, article 13, 2008.

[150] D. S. Sharp and N. L. Benowitz, "Pharmacoepidemiology of the effect of caffeine on blood pressure," Clinical Pharmacology and Therapeutics, vol. 47, no. 1, pp. 57-60, 1990.

[151] W. C. Winkelmayer, M. J. Stampfer, W. C. Willett, and G. C. Curhan, "Habitual caffeine intake and the risk of hypertension in women," Journal of the American Medical Association, vol. 294, no. 18, pp. 2330-2335, 2005.

[152] I. Sudano, L. Spieker, C. Binggeli et al., "Coffee blunts mental stress-induced blood pressure increase in habitual but not in nonhabitual coffee drinkers," Hypertension, vol. 46, no. 3, pp. 521-526, 2005.

[153] R. Corti, C. Binggeli, I. Sudano et al., "Coffee acutely increases sympathetic nerve activity and blood pressure independently of caffeine content role of habitual versus nonhabitual drinking," Circulation, vol. 106, no. 23, pp. 2935-2940, 2002.

[154] D. J. Morris, E. Davis, and S. A. Latif, "Licorice, tobacco chewing, and hypertension," The New England Journal of Medicine, vol. 322 , no. 12 , pp. 849-850, 1990.

[155] L. J. Appel, T. J. Moore, E. Obarzanek, W. M. Vollmer, L. P. Svetkey, F. M. Sacks et al., "A clinical trial of the effects of dietary patterns on blood pressure. DASH Collaborative Research Group," The New England Journal of Medicine, vol. 336, no. 16, pp. 1117-1124, 1997.

[156] L. P. Svetkey, D. Simons-Morton, W. M. Vollmer et al., "Effects of dietary patterns on blood pressure: subgroup analysis of the Dietary Approaches to Stop Hypertension (DASH) randomized clinical trial," Archives of Internal Medicine, vol. 159, no. 3, pp. 285-293, 1999.

[157] D. E. Epstein, A. Sherwood, P. J. Smith, L. Craighead, C. Caccia, P. H. Lin et al., "Determinants and consequences of adherence to the dietary approaches to stop hypertension diet in AfricanAmerican and white adults with high blood pressure: results from the ENCORE trial," Journal of the Academy of Nutrition and Dietetics, vol. 112, no. 11, pp. 1763-1773, 2012.

[158] M. Mitka, "DASH dietary plan could benefit many, but few hypertensive patients follow it," Journal of the American Medical Association, vol. 298, no. 2, pp. 164-165, 2007.

[159] W. M. Vollmer, F. M. Sacks, J. Ard et al., "Effects of diet and sodium intake on blood pressure: subgroup analysis of the DASH-sodium trial," Annals of Internal Medicine, vol. 135, no. 12, pp. 1019-1028, 2001.

[160] J. A. Blumenthal, M. A. Babyak, A. Hinderliter et al., "Effects of the DASH diet alone and in combination with exercise and weight loss on blood pressure and cardiovascular biomarkers in men and women with high blood pressure: the ENCORE study," Archives of Internal Medicine, vol. 170, no. 2, pp. 126-135, 2010.

[161] T. T. Fung, S. E. Chiuve, M. L. McCullough, K. M. Rexrode, G. Logroscino, and F. B. Hu, "Adherence to a DASH-style diet and risk of coronary heart disease and stroke in women," Archives of Internal Medicine, vol. 168, no. 7, pp. 713-720, 2008.
[162] A. Parikh, S. R. Lipsitz, and S. Natarajan, "Association between a DASH-like diet and mortality in adults with hypertension: findings from a population-based follow-up study," American Journal of Hypertension, vol. 22, no. 4, pp. 409-416, 2009.

[163] E. B. Levitan, A. Wolk, and M. A. Mittleman, "Relation of consistency with the dietary approaches to stop hypertension diet and incidence of heart failure in men aged 45 to 79 years," American Journal of Cardiology, vol. 104, no. 10, pp. 1416-1420, 2009.

[164] E. B. Levitan, A. Wolk, and M. A. Mittleman, "Consistency with the DASH diet and incidence of heart failure," Archives of Internal Medicine, vol. 169, no. 9, pp. 851-857, 2009.

[165] E. Obarzanek, F. M. Sacks, W. M. Vollmer et al., "Effects on blood lipids of a blood pressure-lowering diet: the Dietary Approaches to Stop Hypertension (DASH) Trial," American Journal of Clinical Nutrition, vol. 74, no. 1, pp. 80-89, 2001.

[166] S. T. Chen, N. M. Maruthur, and L. J. Appel, "The effect of dietary patterns on estimated coronary heart disease risk results from the Dietary Approaches to Stop Hypertension (DASH) trial," Circulation, vol. 3, no. 5, pp. 484-489, 2010.

[167] L. Azadbakht, P. Mirmiran, A. Esmaillzadeh, T. Azizi, and F. Azizi, "Beneficial effects of a dietary approaches to stop hypertension eating plan on features of the metabolic syndrome," Diabetes Care, vol. 28, no. 12, pp. 2823-2831, 2005.

[168] L. De Koning, S. E. Chiuve, T. T. Fung, W. C. Willett, E. B. Rimm, and F. B. Hu, "Diet-quality scores and the risk of type 2 diabetes in men," Diabetes Care, vol. 34, no. 5, pp. 1150-1156, 2011.

[169] A. H. Lichtenstein, L. J. Appel, M. Brands et al., "Diet and lifestyle recommendations revision 2006: a scientific statement from the American heart association nutrition committee," Circulation, vol. 114, no. 1, pp. 82-96, 2006.

[170] Y. Handelsman, J. I. Mechanick, L. Blonde, G. Grunberger, Z. T. Bloomgarden, G. A. Bray et al., "American Association of Clinical Endocrinologists Medical Guidelines for Clinical Practice for developing a diabetes mellitus comprehensive care plan," Endocrine Practice, vol. 17, supplement 2, pp. 1-53, 2011.

[171] US Department of Health and Human Services, "Your Guide To Lowering Your Blood Pressure With DASH," 2006, http://www.nhlbi.nih.gov/health/public/heart/hbp/dash/new_ dash.pdf

[172] L. J. Appel, "Effects of comprehensive lifestyle modification on blood pressure control: main results of the PREMIER clinical trial," Journal of the American Medical Association, vol. 289, no. 16, pp. 2083-2093, 2003.

[173] B. Armstrong, A. J. Van Merwyk, and H. Coates, "Blood pressure in Seventh Day Adventist vegetarians," American Journal of Epidemiology, vol. 105, no. 5, pp. 444-449, 1977.

[174] B. Armstrong, H. Clarke, and C. Martin, "Urinary sodium and blood pressure in vegetarians," American Journal of Clinical Nutrition, vol. 32, no. 12, pp. 2472-2476, 1979.

[175] B. J. Pettersen, R. Anousheh, J. Fan, K. Jaceldo-Siegl, and G. E. Fraser, "Vegetarian diets and blood pressure among white subjects: results from the Adventist Health Study-2 (AHS-2)," Public Health Nutrition, vol. 15, no. 10, pp. 1909-1916, 2012.

[176] B. M. Margetts, L. J. Beilin, R. Vandongen, and B. K. Armstrong, "Vegetarian diet in mild hypertension: a randomised controlled trial," British Medical Journal, vol. 293, no. 6560, pp. 1468-1471, 1986.

[177] I. L. Rouse, B. K. Armstrong, L. J. Beilin, and R. Vandongen, "Blood-pressure-lowering effect of a vegetarian diet: controlled trial in normotensive subjects," The Lancet, vol. 1, no. 8314, pp. $5-10,1983$. 


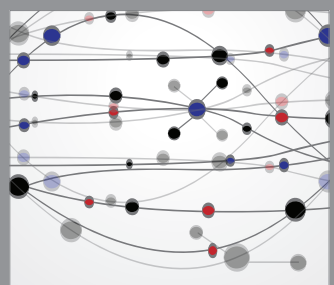

The Scientific World Journal
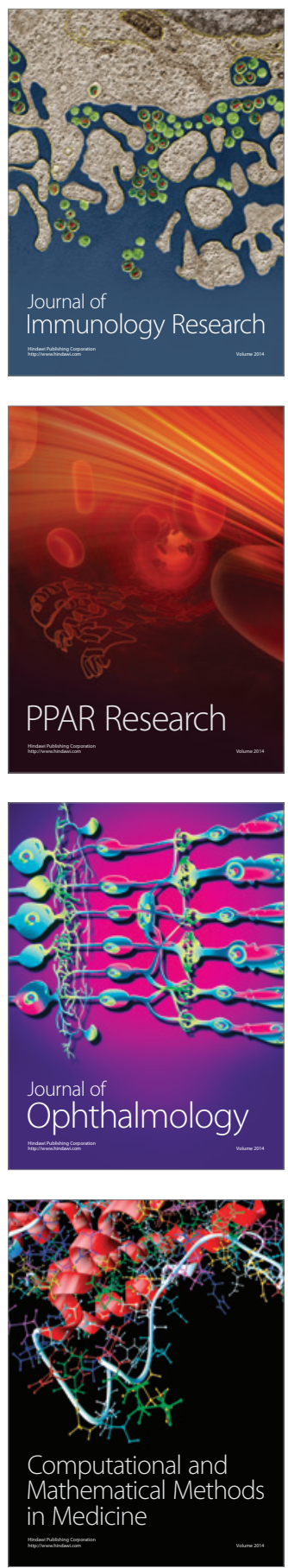

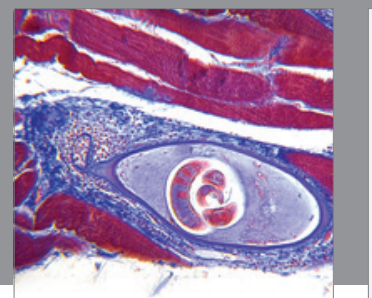

Gastroenterology

Research and Practice
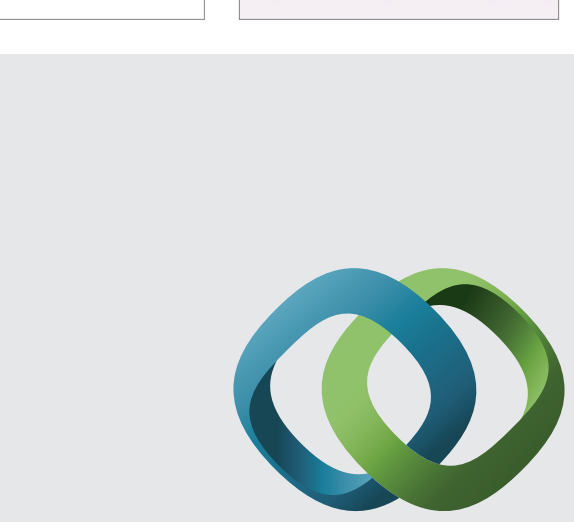

\section{Hindawi}

Submit your manuscripts at

http://www.hindawi.com
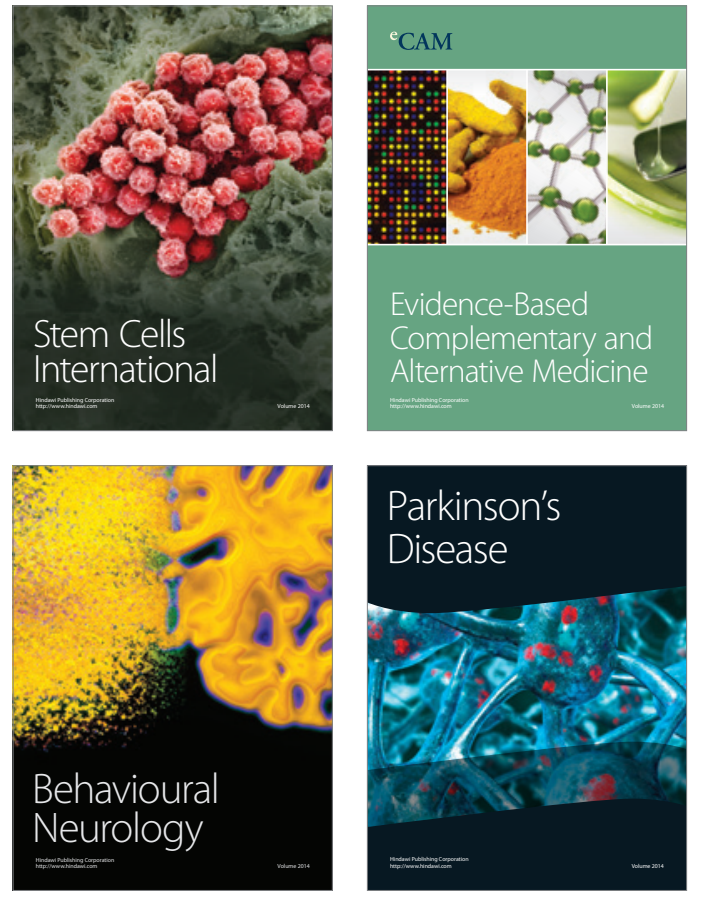
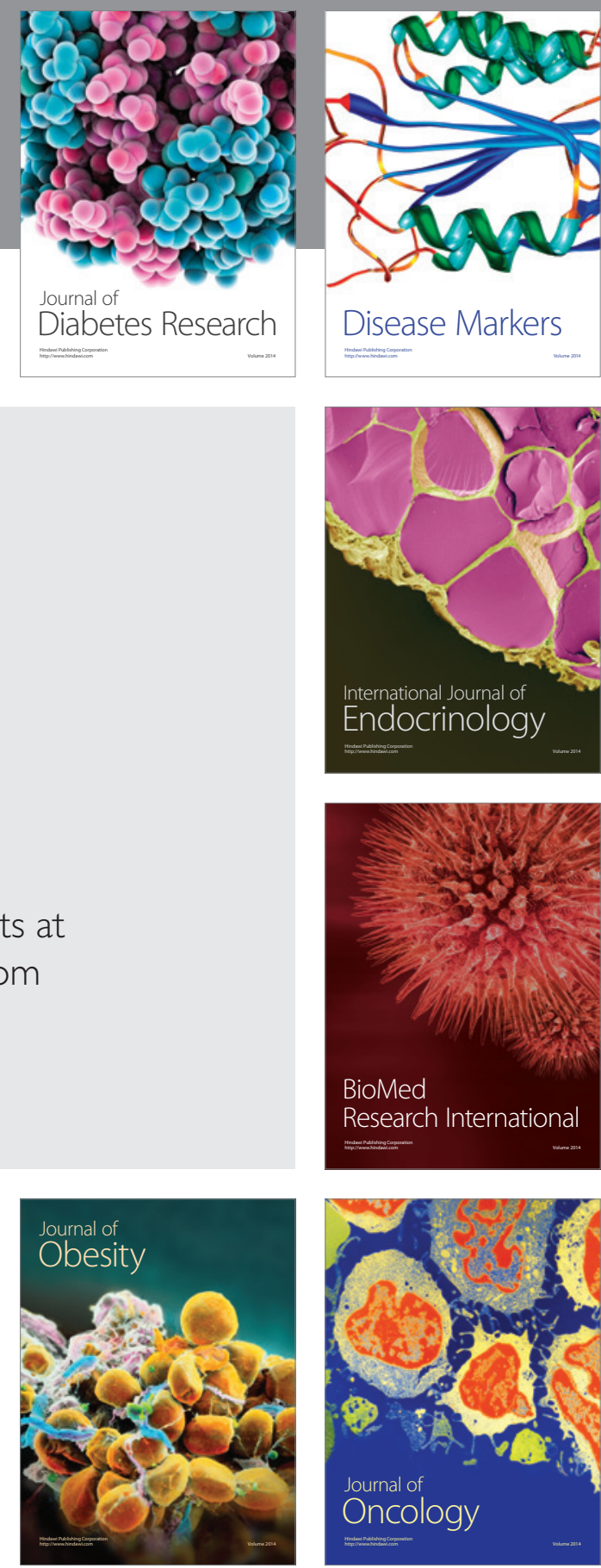

Disease Markers
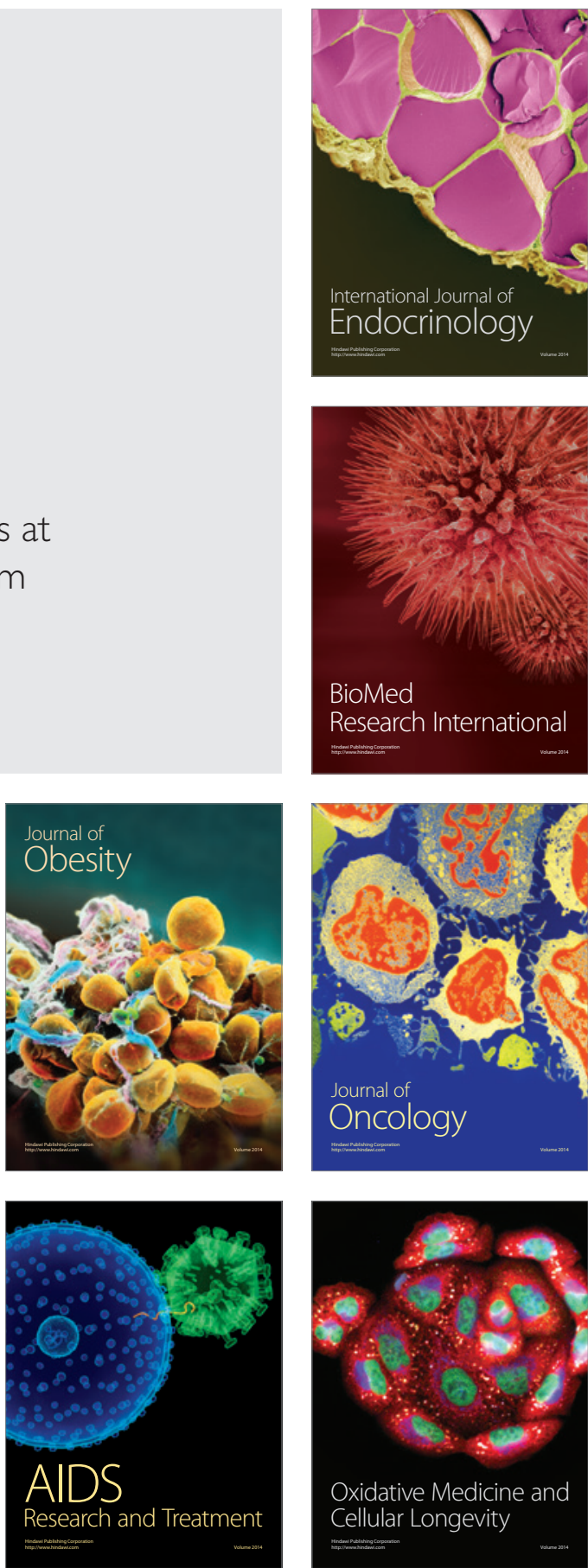